\title{
Movilizaciones y escisiones de la comunidad científica en tiempos de guerra
}

\author{
Leoncio López-Ocón Cabrera \\ Departamento de Historia de la Ciencia, Instituto de Historia, Centro de Ciencias Humanas y Sociales, C/ Albasanz n 26-28. 28037 Madrid \\ CSIC \\ e-mail: leoncio.lopez-ocon@cchs.csic.es
}

\begin{abstract}
Submitted: 13 January 2014. Accepted: 31 March 2014
RESUMEN: El objetivo de este ensayo es triple. Por una parte se ofrece una visión panorámica de los vínculos entre ciencia, guerra y universidad durante tres momentos clave definitorios de la contemporaneidad: la Revolución francesa, la Gran Guerra y la Segunda Guerra Mundial. Por otro lado se presta atención particular a las movilizaciones de actores, a las transformaciones en los sistemas de organización de la ciencia y a la creación de artefactos técnicos en cada una de las mencionadas coyunturas belicistas. Y en tercer lugar se considera el hecho de que la comunidad científica tiende a escindirse en coyunturas críticas. Durante la revolución francesa el mesianismo revolucionario politizó a la ciencia y dividió a los científicos en el interior de su país. Un siglo después, a principios del siglo XX, dominó la escena política el mesianismo nacionalista, responsable de que la misma escisión separase a los científicos no sólo en el interior de sus respectivos Estados, sino también entre los diversos Estados integrantes de la comunidad internacional.
\end{abstract}

PALABRAS CLAVE: ciencia; universidad; Revolución francesa; primera guerra mundial; segunda guerra mundial; Carnot; Fritz Haber; Robert Oppenheimer

Citation / Cómo citar este artículo: López-Ocón Cabrera, Leoncio (2014). "Movilizaciones y escisiones de la comunidad científica en tiempos de guerra". Culture \& History Digital Journal, 3(1): e008. doi: http://dx.doi.org/10.3989/chdj.2014.008

\begin{abstract}
Mobilizations and divisions of the scientific community in wartime.- This paper has a triple objective. On the one hand, it pretends to give an overview of the links between science, war and university during three key moments of contemporary history: the French Revolution, the Great War and the Second World War. Furthermore special attention is paid to the mobilization of actors, to changes in the organizational processes of science and to the creation of technical artifacts in each of the above warmongers situations. Thirdly we consider the fact that the scientific community tends to split at critical junctures. During the French Revolution the revolutionary messianism politicized science and it divided scientists within their country. A century later, in the early twentieth century, the nationalist messianism dominated the political scene. This messianism raised controversy among scientists, not only within their respective states, but also between the various states of the international community.
\end{abstract}

KEYWORDS: science; university; French Revolution; First World War; Second World War; Carnot; Fritz Haber; Robert Oppenheimer

Copyright: $\odot 2014$ CSIC. This is an open-access article distributed under the terms of the Creative Commons AttributionNon Commercial (by-nc) Spain 3.0 License.

Las relaciones entre la ciencia y la guerra han sido estrechas a lo largo de la historia. Se remontan a tiempos antiguos. Son bien conocidas, por ejemplo, las contribuciones del matemático e ingeniero Arquímedes quien diseñó diversos inventos -como la manus férrea, artilu- gio capaz de sacar barcos enemigos del agua- para mejorar la defensa de su ciudad natal Siracusa durante las segundas guerras púnicas.

Pero, como intentaré explicar a continuación, esas interrelaciones han caracterizado sobre todo nuestra 
edad contemporánea, según ha destacado una abundante bibliografía (Sánchez Ron, 2007; Pestre, 2005; Krige y Pestre, 1997; Forman y Sánchez Ron, 1996; SchroederGudehus, 1978). Han marcado a sangre y fuego el convulso y dramático siglo XX, definido en 1946 por Albert Camus como el "siglo del miedo", miedo producido por las aplicaciones bélicas de la ciencia que podrían destruir la vida en la tierra ${ }^{1}$.

Ahora bien, las conexiones entre universidad, ciencia, y guerra ya no son tan claras en los tiempos modernos, pues es bien conocido que instituciones tan representativas de la ciencia moderna como la Royal Society y l'Académie des Sciences nacieron al margen de la universidad. Hay que tener en cuenta además que, al iniciarse el ciclo de las revoluciones atlánticas con las que se inauguró nuestra contemporaneidad, las universidades europeas y americanas enseñaban saberes que, excepto la medicina, incidían poco en el conocimiento de la realidad. Ilustrados, como Diderot y D'Alembert, las consideraban reliquias del corporativismo medieval, necesitadas urgentemente de una profunda renovación ${ }^{2}$.

En aquel entonces, con independencia de la fecha de su fundación, las universidades del mundo occidental presentaban una serie de rasgos comunes. Eran corporaciones autogobernadas y descompuestas en facultades, beneficiarias de variados privilegios judiciales, fiscales y académicos. Su acceso estaba circunscrito solo a aspirantes masculinos, que acreditasen un suficiente dominio del latín como lengua de uso general en el terreno de la transmisión y la difusión del conocimiento. La organización de las facultades era deudora de la vieja separación medieval al estar divididas en cuatro grandes ramas: gramática y filosofía -englobadas ambas como artesteología, derecho civil y canónico, y medicina. Su principal función era la de enseñar y examinar en su respectiva parcela, disfrutando en ella de una supremacía educativa que se sustentaba en un monopolio en el otorgamiento de grados, recibido de la Iglesia o del Estado. Se convertían así en lugar de paso obligado para todo aquel que pretendiese incorporarse al desempeño de ciertas profesiones de especial relevancia (Bermejo, 2008: 50-51).

Estas características eran más o menos comunes a las universidades existentes en el siglo XVIII en el ámbito cultural europeo: cuarenta y cinco germánicas, fuesen protestantes o católicas, veintiocho españolas, contando las americanas, veinticuatro francesas, dieciocho italianas, cuatro escocesas, dos inglesas, y dos en Portugal- las de Coimbra y Evora (Bermejo, 2008: 56).

Hecha esta puntualización acerca de las dificultades de establecer una relación unívoca y directa entre los tres soportes del trípode ciencia, guerra, universidad a lo largo de los períodos históricos que han configurado nuestra contemporaneidad, quisiera ofrecer a continuación una visión panorámica de sus vínculos atendiendo a tres coyunturas específicas: el período de las revoluciones atlánticas prestando particular atención a la revolución francesa ${ }^{3}$; la Gran Guerra de 1914-1918 y la Segunda Guerra Mundial.
En cada una de esas coyunturas se produjeron movilizaciones de múltiples actores relacionados con la producción y distribución de conocimientos, y transformaciones en los sistemas de organización de la ciencia y en la creación de artefactos técnicos que garantizasen la victoria sobre los enemigos. Explicar algunas características de esos fenómenos es el hilo conductor de la reflexión que se efectúa a continuación. Para ello me aproximaré a las tres coyunturas bélicas, a tres escenarios de la historia contemporánea, que conviene contemplar desde diferentes puntos de vista como hacemos cuando observamos un panorama, como el que existe en el museo moscovita que nos evoca la batalla de Borodino.

\section{LA RÉPUBLIQUE N'A PAS BESOIN DES SAVANTS NI DES CHIMISTES}

El primer escenario está definido por la frase apócrifa -La République n'a pas besoin des savants ni des chimistes- que se ha atribuido a diversos robiesperristas, como Jean-Baptiste Coffinhal, que juzgaron y condenaron a Lavoisier a la guillotina en $1794 .{ }^{4}$ Es bien conocido que los hechos desmienten tan pretenciosa sentencia, como se aprecia en el informe efectuado el 3 de enero de 1795 por el médico y químico Antoine François de Fourcroy (1755-1809), un notorio jacobino en representación del Comité de Salud Pública. En él expuso a la Convención nacional las decisivas aportaciones efectuadas por la ciencia en la defensa de la República de tal manera que las luces de sus colegas científicas se habían convertido en "el ancla de la salvación de todos". Y en otro informe este reorganizador de la enseñanza científica y médica insistió en sus consideraciones. Subrayó entonces que la guerra había sido la ocasión propicia para que la República francesa pudiese desarrollar todo el poder de sus ingenieros y científicos (Salomon, 1974: 30).

En efecto, la movilización de los científicos en el bienio 1793-1794 fue decisiva para salvar la naciente república francesa que en el año de 1793 se encontraba ante el abismo, falta de armamento y materias primas para contener la amenaza de las potencias europeas monárquicas, coaligadas para derribar el régimen republicano y evitar la contaminación de las ideas revolucionarias. Defender eficazmente la nación en armas requirió el concurso del mayor número posible de técnicos e ingenieros que hasta entonces estaban mal representados en la Convención o en el gobierno revolucionario. El instrumento para movilizarlos fue la creación - el 6 de abril de 1793 - del Comité de Salud Pública por parte de la Convención. Su primer presidente, Guyton de Morveau, decidió confiar misiones técnicas a expertos científicos para crear los instrumentos adecuados que garantizasen la defensa de la República y reconstruyesen las infraestructuras del país, cuyas carreteras, puentes, puertos y arsenales estaban abandonados. Así, una de las comisiones creadas por Guyton de Morveau fue la de obras públicas. En ella estaban presentes cinco quí- 
micos -Berthollet, Chaptal, Fourcroy, el mismo Guyton de Morveau, Vauquelin-; un físico: Hassenfratz; dos ingenieros -Lamblardie y Prieur de la Côte-d'Or-; y dos matemáticos -Monge y Vandermonde-, representantes en su mayor parte del ala izquierda de la ciencia francesa. En esa coyuntura bélica decisiva los científicos participan, por primera vez activamente, en los asuntos de Estado para conducirlo a la victoria militar.

Cifras, artefactos técnicos y rostros son elocuentes respecto a ese compromiso que llevará a que los representantes de la ciencia tomen el poder en la Francia revolucionaria. El informe de Fourcroy a la Convención, al que aludí anteriormente, estaba respaldado por una serie de datos que muestran la eficacia lograda hacia 1795 por los científicos en la producción acelerada y masiva de armamento y en el impulso dado a la industria química para el aprovisionamiento de soda y potasio: 6.000 fusiles por día, 30 fundiciones -en lugar de las 4 existentes en 1789- que producían 13.000 cañones, una cosecha de nitratos, vital para la fabricación de pólvora, doce veces superior a la de 1792 (Dhombres, 1988: 60).

Estos guarismos revelaban la importancia del esfuerzo colectivo de los científicos movilizados por la Revolución para mejorar la defensa nacional ${ }^{5}$, la cual se manifestó también en las aplicaciones bélicas que se dieron a dos descubrimientos previos como fue el caso del telégrafo aéreo y de los aerostatos.

Claude Chappe presentó su telégrafo a la Asamblea legislativa en marzo de 1792 . Hizo hincapié en su valor militar al resaltar que su invento permitiría a los legisladores transmitir sus órdenes a los ejércitos establecidos en las fronteras y recibir la respuesta inmediatamente durante la misma sesión. El proyecto se adoptó y en julio de 1793 se construyó la primera línea entre Paris y Lille, un punto neurálgico del frente del norte.

Por otra parte, en ese mismo mes de julio de 1793, el químico Guyton de Morveau, presidente del Comité de Salud Pública, expuso a sus colegas de comité las ventajas militares aportada por el uso de los aerostatos: podrían informar de los movimientos de los ejércitos enemigos, transmitir órdenes a las tropas, lanzar propaganda de las nuevas ideas revolucionarias sobre las líneas enemigas. Surgió entonces la aerostación militar, una aplicación para la guerra del invento de los hermanos Joseph y Etienne Montgolfier, producto de la investigación científica promovida por la nueva química de Lavoisier. Los hermanos Montgolfier tuvieron, en efecto, la idea de encerrar en un espacio cerrado en forma de globo un gas más ligero que el aire para que el artilugio pudiera ascender en la atmósfera. Lograron el primer lanzamiento de un globo aerostático el 5 de junio de 1783. Una década después, en la batalla de Fleurus de 26 de junio de 1794 que abrió las puertas de Bélgica a Francia, las tropas de este país pudieron vencer porque el general Jourdan pudo observar los movimientos de las tropas enemigas anglo-holandesas desde un globo aerostático. Esta nueva arma estratégica operacional revolucionó entonces el arte de la guerra.
Señalemos también que si hay un rostro que representa la estrecha involucración entre ciencia y república en aquella coyuntura, y la eficaz movilización de los savants decididos a ganar la guerra, ese es el del ingeniero militar, matemático y filósofo Lázaro Carnot (17531823). Diputado en la Convención, tras imponer la autoridad republicana en el ejército del Norte, se incorporó en agosto de 1793 al grupo de nueve integrantes del Comité de Salud Pública que tenía poderes extraordinarios para salvar la República de la guerra civil y de las agresiones externas. Allí pone al servicio de la guerra todos sus conocimientos científicos y técnicos y encarna la ingeniería de la guerra. Organiza a través del decreto presentado a la Convención el 23 de agosto de ese año 1793 el gran movimiento de movilización general que permite a la República crear diez ejércitos como escudos protectores de su perímetro fronterizo. Ejerce de jefe de estado mayor de esa imponente maquinaria bélica en la que interviene en enero de 1794 una masa heterogénea de casi un millón de hombres, soldados-ciudadanos que constituyen la columna vertebral de la nación en armas. Él mismo calcula todos los planes de batalla. Cuando se produce el éxito para las tropas revolucionarias en la batalla de Fleurus, a la que ya se ha aludido, el 8 messidor del año II de la República, Carnot obtendrá el título de "organizador de la victoria".

Plenamente convencido del protagonismo que han de asumir los ingenieros y los científicos en el gobierno de la Nación y en que la Revolución señalaba el inicio de una nueva era impregnada de espíritu científico, Carnot puso en práctica estas convicciones cuando ejerció el poder. Privilegia entonces sistemáticamente a los expertos que muestran en la marcha del Estado sus competencias profesionales e intelectuales y reestructura el sistema educativo en beneficio de los científicos. Él es uno de los impulsores de la fundación de l'Ecole polytechnique, dedicada a formar alumnos leales tanto a la causa de las ciencias como a la de la República ${ }^{6}$.

Carnot, que también será a partir del 4 de noviembre de 1795 uno de los cinco integrantes del Directorio, simboliza la fuerza del "lobby" científico en el período revolucionario (Dhombres, 1989). Los representantes del conjunto de saberes científicos, sean matemáticos o economistas, físicos, químicos, naturalistas o médicos, se introducen de golpe en la política, no individualmente, sino en bloque (Serres, 1991). Y así el astrónomo Jean Sylvain Bailly (1736-1793) fue el primer presidente de la Asamblea constituyente y el primer alcalde de París; Condorcet pasó de la Asamblea legislativa a la Convención, de la que Lacepède también era miembro; Laplace fue senador; Fourier, prefecto y Monge, Arago y Chaptal, ministros

Esta profunda interrelación entre saber y poder se mantendrá durante el período napoleónico cuando el geómetra Napoleón Bonaparte (1769-1821) se apoderó del poder militar y civil. Su carrera había sido impulsada precisamente por Lázaro Carnot quien, siendo miembro del Directorio, eligió al joven general Bonaparte como jefe del ejército de Italia, donde obtuvo decisivas victo- 
rias contra los ejércitos austriacos. Durante su dirección de los destinos de la Francia revolucionaria los científicos continuarán sus relaciones privilegiadas con el poder político (Dhombres, 1989: 709-731).

Además la gran expedición que organizó Napoleón en Egipto inauguró un modelo que definiría las acciones bélicas extraeuropeas de la era del imperialismo: el de poner sus conocimientos al servicio del dominio europeo sobre otras culturas. A partir del afán francés de vencer a los británicos en tierras egipcias y asegurar así su hegemonía colonial en África y Asia, el binomio cienciaimperialismo se revelaría imparable.

Para cerrar nuestra aproximación a este primer cuadro insistamos en nuestro planteamiento inicial: en los inicios del siglo XIX la relación entre ciencia y guerra era muy estrecha, pero la vinculación entre los tres elementos del trípode ciencia-guerra-universidad era más laxa.

Un siglo después, sin embargo, se incrementó notablemente la interrelación entre los elementos de ese triángulo creando una densa trama de intereses y acciones compartidas entre el aparato militar, el sistema científico y el ámbito universitario. Así se puede constatar al aproximarnos a la Gran Guerra, iniciada en el verano de 1914, definida recientemente por el novelista francés Jean Echenoz, como "la primera guerra industrial" y la "peor carnicería de la historia" al reflexionar sobre su novela $14 .^{7}$

En los cuatro años que duró aquella conflagración mundial los científicos se comportaron como aprendices de brujo, como vamos a intentar ver brevemente a continuación.

Pero antes de abordar el segundo momento de esta reflexión, quisiera destacar cómo la comunidad científica tiende a escindirse en coyunturas críticas. Durante las revoluciones atlánticas el mesianismo revolucionario subyacente a ellas politizó a la ciencia y dividió a los científicos en el interior de su país, con trágicas consecuencias en algunos casos, como le sucedió a Lavoisier. Un siglo después, a principios del siglo XX, domina la escena política el mesianismo nacionalista, responsable de que la misma escisión separe a los científicos no sólo en el interior de su país, sino también entre los países. Se rompía así una de las características del conocimiento científico, como es su carácter cosmopolita o universalista.

\section{APRENDICES DE BRUJO}

"Las lámparas se están apagando en toda Europa; no las volveremos a ver encendidas en toda nuestra vida". Estas fueron las reflexiones premonitorias de sir Edward Grey cuando en el verano de 1914 se desencadenó la Primera Guerra Mundial (Stern, 2003: 125). Los científicos se implicaron masivamente en la gigantesca maquinaria bélica que se puso en marcha en los múltiples frentes que se abrieron en el continente europeo. Sus lealtades, multiestratificadas -pues se refieren a la familia, a la institución, a la disciplina, a la nación- y a menudo antagónicas (Cornwell 2005: 30) se decantaron hacia sus respectivos Estados naciones. Así sucedió con los científicos vinculados a sistemas universitarios centralistas, muy dependientes de una política oficial de ayuda a la investigación científica, relativamente escasa, como sucedía en la Francia de la Tercera República. Y también afectó a los que dependían de un sistema educativo regido por las reglas del laissez-faire donde los gobiernos centrales se abstenían de ayudar a la investigación científica, como sucedía en los casos británico y alemán. En esos países, las empresas industriales fueron los principales agentes promotores de la investigación científica llevada a cabo en las universidades o en instituciones ad hoc. Así, el Instituto Nacional de Investigaciones Científicas y Técnicas creado por Helmholtz en 1888 estaba financiado en su arranque por el industrial Siemens y muchos mecenas privados sostenían la multitud de laboratorios bien equipados de las universidades alemanas.

Pertenecieran a cualquiera de las alianzas o ejes políticos en pugna, los científicos de uno y otro bando aconsejaron a sus respectivos gobiernos acerca de los programas militares que dependían de los conocimientos científicos y técnicos acumulados durante el siglo XIX, conocido como la era de la ciencia. Se implicaron además con ahínco en la producción y movilización en masa de nuevas armas, fuesen tanques, submarinos, dirigibles, aviones o gases, quizás la más letal de todas ellas, identificada con la figura de Fritz Haber. En él me voy a detener, pues su trayectoria es reveladora de cómo los científicos alemanes, formados en las mejores universidades europeas existentes en el siglo XIX, se vieron arrastrados a ser aprendices de brujo, co-responsabilizándose de la "peor carnicería de la historia" en la que murieron más de nueve millones de combatientes.

Es sabido que el estallido de la guerra en agosto de 1914 fue recibido en toda Europa en medio de una gran exaltación nacional. En el imperio alemán fue particularmente intensa. Ante la amenaza extranjera los científicos se movilizaron masivamente, máxime cuando ellos habían sido actores fundamentales en la construcción de la grandeza alemana, cuyos pilares estaban basados en la combinación de poderío militar y cultivo de la Wissenschaft. De hecho, esa singular combinación había permitido a Alemania, y en concreto a Berlín, convertirse en la Meca internacional de la ciencia al finalizar la primera década del siglo XX.

En esa movilización destacó el que sería considerado el padre de la guerra química, Fritz Haber, director desde 1911 del Instituto Kaiser Wilhelm para la Química Física y Electroquímica en el suburbio berlinés de Dahlem que Friedrich Althoff, el principal responsable de las universidades prusianas, quería transformar en un Oxford alemán.

Iniciada la guerra, el prestigioso químico Fritz Haber, de origen judío, pero convertido al cristianismo, se dedicó en cuerpo y alma a las tareas bélicas, consciente de que la ciencia alemana tenía que contribuir a la victoria 
aportando fuentes alternativas de las materias primas indispensables, importadas en el pasado.

Ayudó decisivamente a los políticos, como Walter Rathenau, que dirigían la división del Ministerio de Guerra dedicada a la distribución de las materias primas. Puso entonces a su instituto de Dahlem en pie de guerra y creó una especie de proyecto Manhattan "avant la lettre". Reclutó a ciento cincuenta "colaboradores científicos" y una cantidad más elevada de personal de distinta índole.

Y organizó el uso a gran escala del proceso de fijación de nitrógeno para conseguir que la producción de ácido nítrico para explosivos y fertilizantes se adecuara a una demanda cada vez mayor. Se le conoce como proceso Bosch-Haber, pues fue desarrollado inicialmente cuando Carl Bosh y Fritz Haber coincidieron en la Universidad de Karlsruhe entre 1894 y 1911. Estaba basado en la síntesis catalítica del amoníaco a partir del dihidrógeno y el dinitrógeno atmosférico en condiciones de alta temperatura y presión. Fue un hito en la industria química, pues independizó la síntesis del amoníaco y de productos nitrogenados - como fertilizantes, explosivos y materias primas químicas-, de los depósitos naturales, especialmente del nitrato de sodio, del que Chile era casi el único productor mundial.

De hecho, en 1916 el Instituto de Haber era capaz de producir 25 millones de toneladas mensuales de salitre, inexistente en Alemania antes de la guerra. De no haber efectuado ese esfuerzo, la capacidad militar de ese país se hubiera agotado en la primavera de 1915 por falta de munición, y el pueblo alemán habría pasado hambre por falta de fertilizantes.

Pero la contribución más conocida de Haber a la guerra fue la elaboración de gas tóxico, arma con la que se pretendía superar el estancamiento mortífero de la guerra de trincheras, contraviniendo su prohibición decretada por la Convención de La Haya de 1907, firmada, entre otros países, por la misma Alemania.

Los denominados soldados de la unidad de gas de Haber no eran cualesquiera: se trataba de jóvenes científicos talentosos. Así en torno a él, que obtuvo el premio Nobel en 1918, se agruparon otros tres futuros premios Nobel: James Franck, Gustav Hertz y Otto Hahn. Todos ellos hicieron propia la reflexión de Haber: "en tiempo de paz, un científico pertenece al mundo, pero en tiempo de guerra pertenece a su país". Sus investigaciones permitieron usar por primera vez el gas cloro el 22 de abril de 1915 contra las tropas francoargelinas en la segunda batalla de Ypres, a la que asistió personalmente Haber. La guerra con gases tóxicos no inclinó la balanza del lado alemán, pero el horror que provocó - la espeluznante asfixia, la ceguera, las muertes, la experiencia incluso para los supervivientes de una muerte en vida- ha pasado a formar parte de manera indeleble de nuestra memoria colectiva, un temprano ejemplo de la ciencia al servicio de unos propósitos satánicos (Stern, 2003: 132).

Haber se convirtió por tanto en el organizador de la ciencia más importante de la Alemania bélica. Así lo reconoció uno de sus hijos, historiador de la ciencia, quien señaló que en su padre "[el alto mando] encontró una mente brillante y un organizador sumamente enérgico, resuelto y posiblemente también sin escrúpulos". Quizás esa falta de escrúpulos esté relacionada con la decisión que tomó su primera esposa, Clara Inmmerwahr, química también y la primera mujer doctorada en la universidad de Breslau, de suicidarse el 15 de mayo de 1915, tras haberse opuesto a la guerra química.

Pero la falta de escrúpulos afectó a muchos otros científicos de otros países contendientes. Francia tuvo en el profesor universitario y premio Nobel de Química de 1912 Víctor Grignard la contraparte de Haber en la guerra del gas franco-alemana, al especializarse en el uso de gases militares - como el fosgeno y el gas mostaza- y explosivos.

Situándonos en terreno francés, diversos estudios han mostrado cómo los médicos se organizaron en una máquina de guerra (Becker, 2000; Delaporte, 2004; Le Naour 2011). Por un lado contra la Alemania de Guillermo II a la que se acusó de llevar a cabo un plan diabólico tendente a destruir la "raza" francesa mediante una guerra total. Pero también contra los "soldados de la vergüenza", es decir los más de cien mil soldados franceses con enfermedades mentales, cuyos síntomas eran la parálisis, los temblores del cuerpo, la mudez, los cuerpos plegados, etc., traumatizados por los horrores de la guerra, que llegaron a ocupar una séptima parte de la camas disponibles de los hospitales entre 1914 y 1918 (Becker, 2000: 144). Se crearon centros neurológicos para tratarlos mediante una electroterapia persuasiva impulsada por el neurólogo Joseph Babinski que acuñó el concepto de "pithiatismo" para designar el conjunto de desórdenes funcionales que no tenían una causa orgánica. Los enfermos de pithiatismo eran sospechosos de tener mala voluntad, es decir de ser simuladores, que no querían afrontar sus responsabilidades en la línea del frente (Darmon, 2001). En 1915 la Sociedad de neurología consideró que no podían ser reformados. Pero un año después un importante neurólogo, Clovis Vincent, apostó por el uso de la violencia como método de curación, considerando que la inyección de dosis masivas de electricidad a los enfermos era el tratamiento más eficaz y más rápido para enviarlos al frente. De modo que mayoritariamente los médicos franceses se pusieron al lado del Estado, convencidos de que su tarea era proporcionar soldados a la patria, olvidándose de que se debían a los enfermos a los que debían de mitigar sus sufrimientos.

La Gran Guerra dejó consternados a los científicos de los pocos países que permanecieron neutrales en aquella contienda.

Uno de ellos fue el catedrático de la Universidad Central de Madrid Santiago Ramón y Cajal, premio Nobel de Medicina y Fisiología en 1906, quien en su autobiografía manifestó cómo "la perturbación producida en los espíritus por la horrenda guerra europea de 1914" fue para su actividad científica "un golpe rudísimo" de manera que "alteró mi salud...y enfrió, por primera vez, 
mis entusiasmos por la investigación". En sus reflexiones el científico español se mostró pesimista al constatar que en las "cruentas crisis de civilización" solo se apreciaban aquellas ciencias que se ponían, "con vergonzosa sumisión, al servicio de los grandes aniquiladores de pueblos" y expresó sus temores ante el futuro de la guerra biológica al comparar el armamento de su ayer - en el que habían predominado aeroplanos, cañones descomunales, gases asfixiantes y lacrimógenos- con los que podría deparar su mañana caracterizado por armas letales como: microbios patógenos, epidemias inoculadas desde las nubes, envenenamiento de los alimentos y las aguas (Ramón y Cajal, 2006: 713-714).

Por su parte, en los países contendientes pocas voces intentaron hacer frente a aquel tsunami de terror y horror entremezclados. Entre los científicos la voz que sonó más alta en contra de la guerra fue la de Albert Einstein, destacado pacifista militante en aquella coyuntura, y que acababa de instalarse en Berlín para tener una cátedra en la universidad sin obligaciones docentes y dirigir el Instituto Káiser Guillermo de Física, gracias a las gestiones llevadas a cabo por su amigo Fritz Haber.

Desde el principio del conflicto bélico Einstein consideró la guerra como una especie de drama suicida en la historia de Europa, un arrebato de locura. Se adhirió al contramanifiesto de octubre de 1914 que lanzó el físico berlinés G.F. Nicolai, nacido Lewinstein, para evitar que Europa sucumbiese al agotamiento y la destrucción por una guerra fratricida y en el que se marcaban distancias con el famoso manifiesto de los 93 sabios y eruditos, entre los que se encontraban Fritz Haber y Paul Ehrlich, en el que se reafirmaba que Alemania no era culpable de haber provocado la guerra.

Su pena y asco ante el desarrollo de los acontecimientos le reafirmaron en su convicción de que "todo nuestro progreso tecnológico, tan elogiado, y la civilización en general, podrían compararse con un hacha en manos de un criminal patológico" (Stern, 2003:130). Pero su estado de ánimo maltrecho no le impidió seguir con sus "pacíficas reflexiones" que culminaron en 1915 con la teoría general de la relatividad.

Tras la Gran Guerra Einstein se convirtió en un héroe mundial, sobre todo a partir del momento en el que el presidente de la Royal Society y Premio Nobel J.J. Thompson manifestó que las observaciones de la expedición británica de A.S. Eddington sobre el eclipse solar de marzo de 1919 corroboraban las desviaciones gravitacionales de la luz que Einstein había supuesto y por lo tanto confirmaban la teoría general de la relatividad. Para Thompson el trabajo de Einstein era "uno de los mayores acontecimientos, tal vez el mayor, de la historia del pensamiento humano".

Pero a medida que crecía su ascendiente internacional empezó a ser objeto de ataques antisemitas en la sociedad alemana, planteando algunos científicos como el premio Nobel Philipp Lenard que la relatividad era "un fraude judío", posición que los nazis enseguida apoyaron. Los delicados equilibrios que habían contribuido a hacer a las universidades alemanas las mejores del mundo a principios del siglo XX empezaron a romperse ante el crescendo de los prejuicios antijudíos.

Así, en 1924, ante un acto discriminatorio contra un compañero judío, el químico Richard Willstätter, premio Nobel de 1915, renunció a su cátedra en la Universidad de Munich y no volvió a entrar en su laboratorio universitario nunca más.

Einstein, por su parte, a medida que la política alemana giraba a la derecha se hizo más radical en su pacifismo de izquierdas, instando a los ciudadanos a rechazar el servicio militar a principios de la década de 1930 . Cuando Hitler alcanzó el poder el 30 de enero de 1933 se encontraba en el Instituto de Tecnología de California, en Pasadena. Inmediatamente se convirtió en un temible opositor al régimen nazi que replicó a sus denuncias quemando sus libros, confiscando sus propiedades y revocando su ciudadanía alemana en 1934. Recuérdese que la Ley de Restauración de la administración pública de abril de 1933 establecía, salvo algunas excepciones, la eliminación de las universidades alemanas de los profesores no arios.

La guerra entre Einstein y el régimen nazi se prolongó varios años y culminó cuando Einstein abandonó sus posiciones pacifistas, y consciente del "pacto con el diablo" que regía la política científica nazi (Cornwell, 2005), envió al presidente Roosevelt un comunicado el 2 de agosto de 1939 en el que le advertía que "trabajos recientes efectuados por E. Fermi y L. Szilard, cuyo manuscrito se me ha comunicado, me llevan a pensar que el elemento uranio podría convertirse en el futuro inmediato en una nueva e importante fuente de energía. Algunos aspectos de la situación actual parecen requerir una gran vigilancia y, dado el caso, una decisión rápida de parte de la Administración. Por eso creo que es mi deber poner ante su atención los hechos y las recomendaciones siguientes...".

Se iniciaba entonces una nueva fase, más intensa, en la asociación histórica del saber y el poder. Culminaría seis años después con la explosión de Hiroshima, reveladora de un mundo nuevo. En él los científicos se mancharon las manos de sangre, según constató el físico norteamericano Robert Oppenheimer en una célebre entrevista con el presidente Harry Truman.

\section{"TENGO LAS MANOS MANCHADAS DE SANGRE"}

Acerquémonos un poco más a aquella coyuntura dramática y a algunos de los rasgos que definieron el papel de los científicos que se involucraron directamente en el desarrollo de la conflagración mundial, que se abrió apenas un mes después del memorándum enviado por Einstein al presidente Franklin D. Roosevelt. Tal escrito lo recibiría el mandatario norteamericano de manos del economista y hombre de negocios, y amigo personal, Alexander Sachs, en octubre de 1939 (Salomon, 1974: 57-58).

Una doble circunstancia explicaría el abandono de Einstein de sus posiciones pacifistas en aquel fatídico 
año 1939. Por una parte, la toma de conciencia de que el rearme de la Alemania hitleriana estaba abriendo una caja de Pandora que amenazaba la implantación de regímenes totalitarios en toda Europa, de lo que era un anticipo la victoria de Franco sobre la España republicana culminada el 1 de abril de 1939. Esa derrota de los republicanos españoles originaría una diáspora de su emergente elite científica ${ }^{8}$, entre la que Einstein tenía no solo admiradores sino buenos amigos, como el físico Blas Cabrera, catedrático de la Universidad Central de Madrid. Por otra parte, la carrera frenética en diversos lugares del mundo para obtener la primera fisión nuclear artificial en cadena, fundamento material de un arma cuyo poder de destrucción sería devastador: la bomba atómica.

De hecho, ya el físico judío de origen húngaro Leo Szilard, una vez exiliado en el Reino Unido, había registrado en 1934 una patente acerca del principio de construcción de la bomba atómica que cedió dos años después al Almirantazgo Británico para asegurar su secreto. Consciente del poder fáustico de las investigaciones que tenía en marcha, intentó durante un tiempo imponer la autocensura a todos los investigadores antinazis. Pero a lo largo de 1939 los acontecimientos se precipitaron.

En efecto, Szilard no logró impedir que en abril de 1939 el físico francés Fréderic Joliot, adscrito al Collège de France, publicase en la revista científica Nature un artículo en el que demostraba cómo operaba el principio de fisión nuclear. Este principio se había descubierto recientemente. Los físicos habían constatado que un átomo de uranio, bombardeado por neutrones, se rompía y liberaba energía. Esta radiactividad artificial tenía una consecuencia que muchos físicos tomaron en consideración: si cada átomo de uranio bombardeado liberaba dos o tres neutrones más, que a su vez pueden bombardear otros átomos de uranio, se provoca una reacción en cadena. En su mencionado artículo Joliot demostraba que era posible obtener 3,5 neutrones por fisión.

Desde entonces una decena de equipos de físicos, distribuidos en Alemania, Inglaterra y la Unión Soviética, orientaron sus investigaciones hacia la ejecución práctica de una reacción en cadena. Pero en esa carrera solo Joliot y sus colaboradores estaban en condiciones de pasar a la etapa práctica de aplicación industrial o militar de la fisión nuclear, aunque tenían que superar problemas de diversa índole. Solucionada la obtención de un enorme volumen de uranio que Joliot necesitaba para sus proyectos de pila atómica - gracias a un acuerdo con una compañía minera belga, propietaria de un yacimiento de uranio en el Congo-, la principal dificultad de su empresa radicaba en la necesidad de aminorar la velocidad de los neutrones emitidos en las primeras fisiones, ya que si iban demasiado rápido no se producía la reacción.

El equipo francés buscó entonces con ahínco un moderador que ralentizase los neutrones sin absorberlos ni provocar rebotes. Se encontró en el deuterio, isótopo del hidrógeno, con el doble de densidad pero idéntico comportamiento, que puede ocupar el lugar del hidróge- no en moléculas de agua, obteniendo así agua "pesada" que tenía un grado de absorción de neutrones muy bajo. Pero este moderador ideal presentaba un gran inconveniente: en el agua existe un átomo de deuterio por cada 6.000 átomos de hidrógeno. De manera que la obtención de agua pesada costaba una fortuna y, a escala industrial, sólo se obtenía en una fábrica del mundo, la de la compañía noruega Norsk Hydro Elekstric, inmortalizada en la película La Bataille de l'eau lourde.

En efecto, en ese film se presenta la batalla que, desencadenada la guerra mundial, libraron banqueros, diplomáticos y físicos ingleses, franceses y noruegos para evitar que los alemanes se apoderasen de veintiséis recipientes de agua pesada, entregados por los noruegos a los franceses, los cuales llegaron finalmente a manos de Joliot. Pero ante la debacle francesa ante el avance alemán, el ministro de Armamento Raoul Dautry, que había trabajado por la integración de la investigación militar y la investigación científica de vanguardia, organizó a mediados de 1940 el envío de ese stock de agua pesada a Inglaterra para evitar su caída en manos alemanas (Latour, 1991).

Entre tanto, en la otra orilla del Atlántico, tuvieron que transcurrir unos meses y producirse el ataque japonés a la base naval norteamericana de Pearl Harbor el 7 de diciembre de 1941 para que los Estados Unidos movilizasen todo su poderío científico-técnico para entrar a fondo en la carrera por obtener la bomba atómica. Se inició entonces, a principios de 1942, lo que se ha conocido como proyecto Manhattan cuyas consecuencias históricas han sido fundamentales por varios motivos ${ }^{9}$.

Nunca como entonces la asociación entre el Estado, la universidad y la industria adquirió tal volumen de esfuerzo científico colectivo, y de inversión económica. Con sus 15.000 sabios e ingenieros, sus 300.000 técnicos y obreros, su costo de dos mil millones de dólares, el Manhattan Engineering District, como fue conocido en un primer momento, se convirtió en la empresa de investigación más grande que jamás se haya realizado.

Pero la escala de la empresa fue menos determinante que su resultado. El proyecto fue dirigido por dos personas muy diferentes: el general Leslie Groves, al que se considera un lobo solitario, y el físico Robert Oppenheimer, brillante, cultivado e hipersensible. Fue él quien encontró el lugar donde se instaló la parte principal del proyecto: Los Alamos, en un lugar perdido de Nuevo México. Las investigaciones realizadas allí, donde se creó una ciudad con cincuenta mil habitantes, se complementaron con los trabajos desarrollados en otros lugares. En la fábrica de Oak Ridge se trató el uranio, la de Hanson se dedicó al plutonio, y en el Laboratorio metalúrgico de Chicago se contrastaron los aceros y otros mecanismos necesarios para su construcción.

Rodeado de los mejores físicos de aquel entonces, como Hans Bethe, Richard Feynman, Enrico Fermi y Leo Szilard, Oppenheimer coordinó las múltiples actividades de carácter técnico vinculadas al proyecto. $\mathrm{E}$ impulsó al mismo tiempo los aspectos teóricos en una 
época en la que los mecanismos de realización de la fisión nuclear y de producción de material fisible no estaban aún dominados. Gracias a sus extraordinarias capacidades, Oppenheimer logró dinamizar ese impresionante complejo científico-militar cuya labor culminó el 16 de julio de 1945 con la explosión de Trinity, la primera bomba atómica, no lejos de Alamogordo. En esa ocasión, que abría una nueva era en la historia de la humanidad, Oppenheimer reaccionó con frialdad manifestando "Esto ha funcionado". Pero Kenneth Bainbridge, físico de la Universidad de Harvard y responsable de la detonación de esa primera bomba atómica, previendo los efectos de ese arma de destrucción masiva, replicó a Oppenheimer con una sentencia que ha pasado a la historia: "Ahora somos unos "cabrones' [o hijos de perra])".

Las previsiones de Bainbridge se cumplieron apenas tres semanas después, cuando el 6 de agosto el bombardero estadounidense Enola Gray, por orden del presidente Harry S. Truman, lanzó una bomba atómica sobre la ciudad de Hiroshima causando la muerte de ciento veinte mil japoneses e hiriendo a más de trescientas sesenta mil personas que sufrirían graves alteraciones genéticas. Tres días después una segunda bomba atómica - la Fat Man- aún más poderosa fue arrojada a la otra ciudad mártir de Nagasaki: setenta y cinco mil de sus doscientos cuarenta mil habitantes murieron instantáneamente.

Los responsables de esas matanzas tuvieron posteriormente problemas de conciencia, como le sucedió a Oppenheimer. Así narra Dean Acheson, que fue secretario de Estado del presidente Truman, una entrevista que tuvo el director científico del proyecto Manhattan con el presidente de Estados Unidos: "Cierta vez, acompañé a Oppie (Oppenheimer) a la oficina de Truman. Oppie se retorcía las manos diciendo: "Tengo manchadas las manos de sangre". Más tarde Truman me dijo: "No me vuelva a traer jamás a ese maldito cretino. No es él quien lanzó la bomba. Fui yo. Estos lloriqueos me ponen enfermo".

\section{CONCLUSIONES}

La secuencia inaugurada por la aventura del Manhattan Project, que transformó a los laboratorios universitarios en anexos de los arsenales, y concluida con los relámpagos causados por las bombas nucleares de Hiroshima y Nagasaki, tuvo pues hondas y trágicas consecuencias en nuestro mundo contemporáneo. Reveló un mundo nuevo caracterizado por el terror nuclear, consolidó la tendencia de "militarización" de la ciencia, que se remontaba a décadas atrás, convirtiéndose los científicos en agentes del Estado, e inauguró la etapa de la big science en la que se ha acelerado la industrialización de la investigación.

Algunas cifras son elocuentes sobre la militarización de una parte significativa de la ciencia en la segunda mitad del siglo XX. En 1968, en los Estados Unidos, más del $50 \%$ de los fondos consagrados a la investiga- ción y al desarrollo correspondían a la defensa, en Francia el $45 \%$ y en el Reino Unidos el $40 \%$. Si se añaden las investigaciones atómicas y espaciales, estos porcentajes se elevaron en Estados Unidos a más del $80 \%$ y a más del $60 \%$ para el Reino Unido y Francia (Salomon, 1974: 67). Otros guarismos también revelan la configuración de una "big science" en el sistema internacional de producción y distribución de conocimientos a lo largo del tercer cuarto del siglo XX. Así, a partir de 1945, y en veinte años, los efectivos totales de la mano de obra empleada en actividades de investigación se multiplicó por diez, de manera que en 1965 más de un millón de personas se dedicaban en Estados Unidos a trabajos de investigación y desarrollo, otras tantas en la Unión Soviética y más de quinientas mil en la Europa occidental (Salomon, 1974: 82).

Ante las consecuencias de esa progresiva "militarización" de la ciencia en los tiempos contemporáneos, la percepción de que los científicos eran instrumentalizados por los políticos y la toma de conciencia de sus responsabilidades como ciudadanos, algunos científicos - y el caso más llamativo es el de Oppenheimer- estimaron que el único refugio del investigador era la "aldea universitaria". Consideraron ese espacio como un lugar de paz, y de estímulo a la creatividad, donde se preserva el sentido de la investigación desinteresada y el cultivo de cualidades humanas esenciales como el intercambio intelectual por sí mismo. Pero todos sabemos, y es lo que he intentado explicar aquí, que esa "aldea científica" está recubierta como nunca por la historia, y que el científico no ha estado ni puede estar al margen de la política. Más bien lo que le corresponde, y este es cierta medida el sentido de la reflexión que ha orientado mi intervención, es no ignorar para quién trabaja, ni quién le financia, y no reducir su vigilancia moral y política para tener una visión reflexiva del presente y de los desafíos futuros, algunos de ellos de gran envergadura como: el continuado abuso del medio ambiente en todo el planeta provocador de un cambio climático; la persistente escalada de las armas bioquímicas; la agresiva creación de patentes sobre elementos de la naturaleza; las anchas y profundas desigualdades sociales que marcan todo el planeta y el colapso de los ideales del libre acceso a la información, entre otros muchos que todos tenemos en mente.

\section{AGRADECIMIENTOS}

Agradezco a Maria Fernanda Rollo y Fátima Nunes haberme dado la oportunidad de presentar una versión preliminar de este texto en el coloquio internacional Guerra, Universidade, Ciencia celebrado en Lisboa el 7 de noviembre de 2013. Este evento fue organizado por el Instituto de Historia Contemporánea de la Facultad de Ciencias Sociales y Humanas de la Universidad Nueva de Lisboa y el Centro de Estudios de Historia y Filosofía de la Ciencia de la Universidad de Evora. En él fui invitado a impartir la conferencia inaugural. 


\section{NOTES}

1. Albert Camus, "Le siècle de la peur", artículo de Combat, noviembre 1946 (sic) [1948], en Essais, Pléiade, Gallimard, 1965, p. 331, citado por Salomon (1989: 10).

2. Acusación vertida en el conocido informe de D. Diderot a Catalina la Grande "Plan d'une université ou d'une éducation publique dans toutes les sciences", en Oeuvres complètes, ed. por R. L Winter, Paris, Le Club Français du Livre, 1969-1973, 15 vols., vol. XI, p. 757 y en el artículo de Jean le Rond D'Alembert y Denis Diderot “Université” de L'Encylopédie, Paris, Neufchastel, 1975-1989, p. 406, citado por Bermejo (2008: 51)

3. Una iniciativa conjunta de la Biblioteca Nacional de Francia y de la Universidad de Stanford permite a los investigadores a partir de principios de 2014 acceder a catorce mil imágenes relacionadas con diversos aspectos de la Revolución francesa y a los archivos parlamentarios que cubren el período que va de 1787 a 1794. Ver http://frda.stanford.edu/fr/catalog [consultado 13/Marzo/2014]

4. Ver al respecto la entrada dedicada a Jean-Baptiste Coffinhal en la Wikipedia francesa. [http://fr.wikipedia.org/wiki/JeanBaptiste_Coffinhal] Consultada el 21 de enero de 2014.

5. Una interesante visión de conjunto del nuevo armamento creado por los científicos movilizados, apoyada en numerosos documentos, en Gillispie (1992).

6. Carnot ha sido objeto de varios estudios biográficos. Cabe destacar entre ellos el de Jean y Nicole Dhombres (1997).

7. Entrevista de Miguel Mora al escritor Jean Echenoz, El País, 20 septiembre 2013. http://cultura.elpais.com/cultura/2013/09/ 19/actualidad/1379621009_917809.html [consultada 21/ enero/ 2014]

8. Parte de esa diáspora científica republicana impulsaría a partir del 1 de marzo de 1940 la revista Ciencia, apoyada en sus primeros años por la editorial Atlante. Una breve aproximación al valor historiográfico de esa revista científica en Leoncio López-Ocón (2014), "Ciencia. Los significados de una revista hispano-americana de ciencias puras y aplicadas en su arranque de 1940", Portal Enlaces del Instituto Internacional para la Educación Superior en América Latina y el Caribe de la UNESCO. http://www.iesalc.unesco.org.ve/index.php?option $=$ com_content\&view $=$ article\&id $=3506$ : ciencia-los-significadosde-una-revista-hispano-americana-de-ciencias-puras-y-aplicadasen-su-arranque-de-1940\&catid=200:circulacion-de-cientificosexpertos-opinan\&Itemid=749\&lang=es [consultado 13/Marzo/ 2014].

9. La bibliografía sobre el proyecto Manhattan es muy amplia. Destacaré las contribuciones recientes de Alex WELLERSTEIN, como su trabajo en la revista Isis (2008), su tesis doctoral presentada en la Universidad de Harvard en octubre de 2010, cuyo capítulo primero "The Need to Know, 1939-1945" está dedicado a los orígenes y desarrollo del proyecto, y su muy interesante bitácora Restricted Data: The Nuclear Secrecy Blog http://blog.nuclearsecrecy.com/ [consultado 14/Marzo/2014]

\section{REFERENCIAS}

Becker, Annette (2000) “Guerre totale et troubles mentaux”. Annales, $55,1: 135-151$.

Bermejo Castrillo, Manuel Ángel (2008) "La Universidad europea entre Ilustración y liberalismo. Eclosión y difusión del modelo alemán y evolución de otros sistemas nacionales". En Filosofia para la Universidad, filosofía contra la Universidad (de Kant a Nietzsche), editor Oncina Coves, Faustino. Editorial Dykinson-Universidad Carlos III. Madrid: 49-165.

Cornwell, John (2005) Los cientificos de Hitler. Ciencia, guerra y el pacto con el diablo. Paidós, Barcelona.

Darmon, Pierre (2001) "Des suppliciés oubliés de la Grande Guerre: les pithiatiques". Histoire, économie et société, $\mathrm{n}^{\circ}$ 1: 49-64.

Delaporte, Sophie (2004) "Discours médical et simulation". En Vrai et faux dans la Grande Guerre, eds. Prochasson, Christophe y Rasmussen Anne. La Découverte, Paris: 218-233.

Dhombres, Nicole (1988) Les savants et la revolution. Cité des Sciences et de l'Industrie, Paris.

Dhombres, Nicole y Jean (1989) Naissance d'un nouveau pouvoir: sciences et savants en France (1793-1824). Payot, Paris.

Dhombres, Jean y Nicole (1997) Lazare Carnot. Fayard, Paris.

Fayet, Joseph (1960) La Révolution française et la Science. Librairie Marcel Rivière, Paris.

Forman, Paul y Sánchez Ron, José Manuel (eds.), (1996) National Military Establishments and the Advancement of Science and Technology: Studies in Twentieth Century History, Kluwer Academic Publishers, Dordrecht.

Gillispie, Charles C. (1992) "Science and Secret Weapons Development in Revolutionary France, 1794-1804: A Documentary History". Historical Studies in the Physical and Biological Sciences, 23: 35-152.

Krige, John y Pestre, Dominique (eds.), (1997) Science in the twentieth century, Harwood Academic Publishers, Amsterdam.

Lafuente, Antonio (2003) "La movilización de la ciencia". Quark, $\mathrm{n}^{\mathrm{o}} 28-29,12 \mathrm{p}$.

Latour, Bruno (1991) "Joliot: punto de encuentro de la historia y de la física". En Historia de las Ciencias, ed. Serres, Michel. Ediciones Cátedra, Madrid: 553-573.

Le Naour, Jean-Yves (2011) Les soldats de la honte. Perrin, Paris.

Pestre, Dominique (2005) Ciencia, dinero y política. Traducido por Ricardo Figueira. Ediciones Nueva Visión, Buenos Aires.

Ramón y Cajal, Santiago (2006) Recuerdos de mi vida, edición de Juan Fernández Santarén. Crítica, Fundación Iberdrola. Barcelona ( $1^{\mathrm{a}}$ ed. 1917).

Salomon, Jean-Jacques (1974) Ciencia y política. Siglo XXI editores, México

Salomon, Jean-Jacques (1989) Science, guerre et paix, Economica, Paris.

Sánchez Ron, José Manuel (2007) El poder de la ciencia: historia social, política y económica de la ciencia (siglos XIX y XX). Crítica, Barcelona.

Schroeder-Gudehus, Brigitte (1978) Les scientifiques et la paix: la communauté scientifique internationale au cours des années 20. Presses de l'Université de Montreal, Montreal. En 2014 se ha reimpreso en formato PDF: http://www.pum.umontreal.ca/ catalogue/les-scientifiques-et-la-paix

Serres, Michel (1991) "Paris 1800". En Historia de las Ciencias, ed. Serres, Michel. Ediciones Cátedra, Madrid: 381-409.

Stern, Fritz (2003) "Juntos y separados: Fritz Haber y Albert Einstein”. En El mundo alemán de Einstein, ed. Stern, Fritz. Paidós, Barcelona: 71-175.

Wellerstein, Alex (2008) "Patenting the bomb: Nuclear weapons, intellectual property and technological control”. Isis, 99: 57-87. doi: $10.1086 / 587556$.

Wellerstein, Alex (2014) "Restricted Data: The Nuclear Secrecy Blog" (http://blog.nuclearsecrecy.com) 